\title{
Establishing a China malaria diagnosis reference laboratory network for malaria elimination
}

\author{
Jian-hai Yin ${ }^{1,2}$, He Yan ${ }^{1,2}$, Fang Huang ${ }^{1,2}$, Mei Li ${ }^{1,2}$, Hui-hui Xiao ${ }^{1,2}$, Shui-sen Zhou ${ }^{1,2}$ and Zhi-gui Xia ${ }^{1,2^{*}}$
}

\begin{abstract}
Background: In China, the prevalence of malaria has reduced dramatically due to the elimination programme. The continued success of the programme will depend upon the accurate diagnosis of the disease in the laboratory. The basic requirements for this are a reliable malaria diagnosis laboratory network and quality management system to support case verification and source tracking.

Methods: The baseline information of provincial malaria laboratories in the China malaria diagnosis reference laboratory network was collected and analysed, and a quality-assurance activity was carried out to assess their accuracies in malaria diagnosis by microscopy using WHO standards and PCR.

Results: By the end of 2013, nineteen of 24 provincial laboratories have been included in the network. In the study, a total of 168 staff were registered and there was no bias in their age, gender, education level, and position.

Generally Plasmodium species were identified with great accuracy by microscopy and PCR. However, Plasmodium ovale was likely to be misdiagnosed as Plasmodium vivax by microscopy.

Conclusions: China has established a laboratory network for primary malaria diagnosis which will cover a larger area. Currently, Plasmodium species can be identified fairly accurately by microscopy and PCR. However, laboratory staff need additional trainings on accurate identification of $P$. ovale microscopically and good performance of PCR operations.
\end{abstract}

Keywords: Malaria diagnosis, Quality assurance, Reference laboratory, Malaria elimination, China

\section{Background}

The epidemiology of malaria in China has changed dramatically [1,2], and the government embarked on a national malaria elimination programme in 2010 to eliminate malaria by 2020 in the country. One of the strategies was to establish a reliable malaria diagnosis laboratory network and a quality management system to support case verification and source-tracking. Quality assurance (QA) of malaria diagnosis was the major indicator of World Health Organization (WHO) procedures for certification of malaria elimination [3]. Consequently, it has been planned to establish the China malaria diagnosis reference laboratory

\footnotetext{
* Correspondence: nipdxzhg@163.com

'National Institute of Parasitic Diseases, Chinese Center for Disease Control and Prevention, Shanghai 200025, Shanghai, People's Republic of China ${ }^{2}$ WHO Collaborating Centre for Malaria, Schistosomiasis and Filariasis, Key Laboratory of Parasite and Vector Biology, Ministry of Health, Shanghai 200025, People's Republic of China
}

\section{Biomed Central}

network in centres for disease control and prevention or institutes of parasitic diseases at different levels mainly in the 24 historical malaria-endemic provinces [4]. Since 2011, one national and 19 provincial malaria diagnosis reference laboratories have been established. The main responsibilities of this network are case diagnosis and verification, capacity training and QA sample bank establishment, technique innovation and technical supports at different levels in order to ensure accuracy and reliability of the results (Figure 1).

The provincial and national laboratories are not only required to directly participate in the patients diagnosis and review samples from hospitals, but should also review samples diagnosed by lower level laboratories. For microscopic diagnosis each year all positive slides must be reviewed by all-level laboratories, and no less than $10 \%$ of negative slides generated in clinics, then no less than $3 \%$ of the former, and no less than $1 \%$ of the former again 


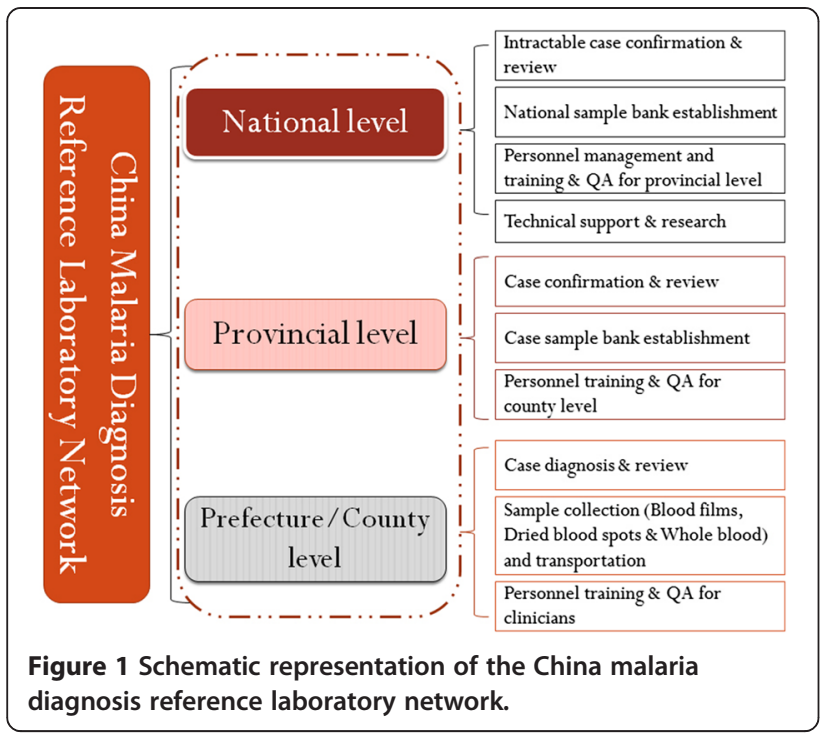

must be reviewed by the county prefecture and provincial levels, respectively. Finally, at least once a year the national laboratory performs reviews and QA activities to cover all the provinces.

Diagnosis in this network requires the use of light microscopy and PCR amplification of the Plasmodium 18s rRNA gene as mandatory methods in the provincial and national laboratories, while rapid diagnostic test (RDT) is optional. This is because using microscopy, Plasmodium parasites can be rapidly characterized and quantified using standard procedures $[5,6]$, although there are some limitations in detecting asymptomatic and sub-patent infections $[7,8]$. In addition, the PCR assays based on 18s rRNA gene amplification have been reliable in detecting circulating parasites [9], and the nested PCR protocol to amplify this gene is widely used in laboratories, clinics and field settings [10-12].

The aim of this programme is to implement an assessment of malaria detection through microscopy and PCR in the provincial laboratories in China, and to strengthen their quality-assured capacity for malaria diagnosis.

\section{Methods}

\section{Collection of baseline information}

A structured questionnaire focusing on the provincial malaria laboratory was provided to each laboratory when they registered in the network.

\section{Participating laboratories and participants}

Nineteen provincial malaria diagnosis reference laboratories were involved in the study. From each laboratory, at least two representatives participated, with one responsible for malaria diagnosis via microscopy and the other by
PCR detection. They were assessed together in the national malaria diagnosis reference laboratory.

\section{Qualitative assessment}

Qualitative assessment of microscopic observations was performed by obtaining 20 slides with Giemsa-stained malaria blood and their standard answers from the external quality assessment programme for communicable diseases (malaria microscopy) in the WHO Western Pacific Region (density unknown) (Table 1) [13]. Staff spent 10 min per slide and followed the operations in basic malaria microscopy [14] to record the results, which were not permitted to be changed after entry. For the PCR assessment, three different dried blood spots, one positive control and one negative control from the blood bank were given to each staff in a blind test for analysis. Plasmodium positive blood samples were previously assessed by the national malaria diagnosis reference laboratory by PCR. DNA was extracted from the blood spots using the QIA amp DNA Mini Kit (Qiagen, USA) and uniform-nested PCR was performed to amplify the multi-copy $18 \mathrm{~s}$ rRNA gene $[4,11,15]$. The first PCR was performed in a $20 \mu \mathrm{l}$ re-

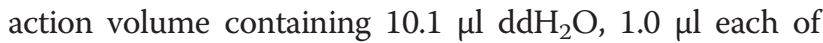
rPLU5, and rPLU6 primers $(10 \mu \mathrm{mol} / \mathrm{L}), 4.9 \mu \mathrm{l}$ buffer mix, 3.0 $\mu \mathrm{l}$ DNA template in the first reaction. The nested PCR contained $11.1 \mu \mathrm{ldd} \mathrm{H}_{2} \mathrm{O}, 1.0 \mu \mathrm{l}$ each of $\mathrm{p} 1$, and $\mathrm{p} 2$ primers $(10 \mu \mathrm{mol} / \mathrm{L}), 4.9 \mu \mathrm{l}$ buffer mix, $2.0 \mu \mathrm{l}$ from the fistt PCR product. The PCR conditions for both PCRs were the following: $94^{\circ} \mathrm{C}$ for $3 \mathrm{~min}$; 34 cycles of $94^{\circ} \mathrm{C}$ for $30 \mathrm{sec}$, $58^{\circ} \mathrm{C}$ for $30 \mathrm{sec}$, and $72^{\circ} \mathrm{C}$ for $60 \mathrm{sec}$; and a final extension at $72^{\circ} \mathrm{C}$ for $5 \mathrm{~min}$. All PCR supplies were from TaKaRa (Dalian, China) and primers were synthesized by Life Technologies ${ }^{\text {Th }}$ (Shanghai, China). Primer sequences are provided in Table $2[4,11,15]$.

\section{Data analysis}

Baseline information from each laboratory was verified by an expert group (two malaria experts from Subcommittee for Schistosomiasis and Parasitic Diseases, Expert Advisory Committee for Disease Control, Ministry of Health, PR China, and two from national malaria diagnosis reference laboratory) through field investigation. All collected data were entered into Microsoft Excel and analysed using SAS 9.2. A $P$ value $<0.05$ was considered statistically significant.

\section{Ethical clearance}

The programme was reviewed and approved by the Ethical Committee of National Institute of Parasitic Diseases, China CDC. All participants provided written informed consent for the study. 
Table 1 Summary of the microscopic examination of malaria blood slides

\begin{tabular}{|c|c|c|c|c|c|c|c|c|c|c|c|c|c|c|c|c|c|c|c|}
\hline & \multicolumn{6}{|l|}{ G1 } & \multicolumn{12}{|l|}{ G2 } & \multirow{2}{*}{$\begin{array}{l}\mathrm{G} 3 \\
\mathrm{~K}\end{array}$} \\
\hline & $\mathrm{C}$ & $M$ & 0 & $\mathbf{P}$ & $\mathbf{R}$ & $S$ & $A$ & B & D & $E$ & $\mathrm{~F}$ & G & $\mathrm{H}$ & 1 & $J$ & $L$ & $\mathrm{~N}$ & $\bar{Q}$ & \\
\hline 13-1-MM01(NE) & $\sqrt{ }$ & $\sqrt{ }$ & $\sqrt{ }$ & $\sqrt{ }$ & $\sqrt{ }$ & $\sqrt{ }$ & $\sqrt{ }$ & $\sqrt{ }$ & $\sqrt{ }$ & $\sqrt{ }$ & $\sqrt{ }$ & $\sqrt{ }$ & $\sqrt{ }$ & $\sqrt{ }$ & $\sqrt{ }$ & $\sqrt{ }$ & $\sqrt{ }$ & $\sqrt{ }$ & $\sqrt{ }$ \\
\hline 13-1-MM02(NE) & $\sqrt{ }$ & $\sqrt{ }$ & $\sqrt{ }$ & $\sqrt{ }$ & $\sqrt{ }$ & $\sqrt{ }$ & $\sqrt{ }$ & $\sqrt{ }$ & $\sqrt{ }$ & $\sqrt{ }$ & $\sqrt{ }$ & $\sqrt{ }$ & $\sqrt{ }$ & $\sqrt{ }$ & $\sqrt{ }$ & $\sqrt{ }$ & $\sqrt{ }$ & $\sqrt{ }$ & $\sqrt{ }$ \\
\hline 13-1-MM04 (P. f) & $\sqrt{ }$ & $\sqrt{ }$ & $\sqrt{ }$ & $\sqrt{ }$ & $\sqrt{ }$ & $\sqrt{ }$ & $\sqrt{ }$ & $\sqrt{ }$ & $\sqrt{ }$ & $\sqrt{ }$ & $\sqrt{ }$ & $\sqrt{ }$ & $\sqrt{ }$ & $\sqrt{ }$ & $\sqrt{ }$ & $\sqrt{ }$ & $\sqrt{ }$ & $\sqrt{ }$ & $\sqrt{ }$ \\
\hline 13-1-MM05 (P. v) & P.O & $\sqrt{ }$ & $\sqrt{ }$ & $\sqrt{ }$ & $\sqrt{ }$ & $\sqrt{ }$ & $\sqrt{ }$ & P.o & $\sqrt{ }$ & $\sqrt{ }$ & $\sqrt{ }$ & $\sqrt{ }$ & $\sqrt{ }$ & $\sqrt{ }$ & $\sqrt{ }$ & $\sqrt{ }$ & $\sqrt{ }$ & $\sqrt{ }$ & $\sqrt{ }$ \\
\hline 13-1-MM06 (P. f) & $\sqrt{ }$ & $\sqrt{ }$ & $\sqrt{ }$ & $\sqrt{ }$ & $\sqrt{ }$ & $\sqrt{ }$ & $\sqrt{ }$ & $\sqrt{ }$ & $\sqrt{ }$ & $\sqrt{ }$ & $\sqrt{ }$ & $\sqrt{ }$ & $\sqrt{ }$ & $\sqrt{ }$ & $P . f+P . V$ & $\sqrt{ }$ & $\sqrt{ }$ & $\sqrt{ }$ & $\sqrt{ }$ \\
\hline 13-1-MM07 (P. v) & $\sqrt{ }$ & $\sqrt{ }$ & $\sqrt{ }$ & $\sqrt{ }$ & $\sqrt{ }$ & $\sqrt{ }$ & P.o & $\sqrt{ }$ & $\sqrt{ }$ & $\sqrt{ }$ & $\sqrt{ }$ & $\sqrt{ }$ & $\sqrt{ }$ & $\sqrt{ }$ & $\sqrt{ }$ & $\sqrt{ }$ & $\sqrt{ }$ & $\sqrt{ }$ & $\sqrt{ }$ \\
\hline 13-1-MM09 (P. f) & $\sqrt{ }$ & $\sqrt{ }$ & $\sqrt{ }$ & $\sqrt{ }$ & $\sqrt{ }$ & $\sqrt{ }$ & $\sqrt{ }$ & $\sqrt{ }$ & $\sqrt{ }$ & $\sqrt{ }$ & $\sqrt{ }$ & $\sqrt{ }$ & $\sqrt{ }$ & $\sqrt{ }$ & $\sqrt{ }$ & $\sqrt{ }$ & $\sqrt{ }$ & $\sqrt{ }$ & $\sqrt{ }$ \\
\hline 13-1-MM10 (P. v) & P.o & P.o & $\sqrt{ }$ & $\sqrt{ }$ & P.o & P.o & $\sqrt{ }$ & P.o & P.o & $\sqrt{ }$ & P.o & P.o & P.o & $\sqrt{ }$ & P.o & $\sqrt{ }$ & P.o & $\sqrt{ }$ & P.o \\
\hline 13-1-MM14 (NE) & $\sqrt{ }$ & $\sqrt{ }$ & $\sqrt{ }$ & $\sqrt{ }$ & $\sqrt{ }$ & $\sqrt{ }$ & $\sqrt{ }$ & $\sqrt{ }$ & $\sqrt{ }$ & $\sqrt{ }$ & $\sqrt{ }$ & $\sqrt{ }$ & $\sqrt{ }$ & $\sqrt{ }$ & $\sqrt{ }$ & $\sqrt{ }$ & $\sqrt{ }$ & $\sqrt{ }$ & $\sqrt{ }$ \\
\hline 13-1-MM15 (P. m) & $\sqrt{ }$ & $\sqrt{ }$ & $\sqrt{ }$ & $\sqrt{ }$ & $\sqrt{ }$ & $\sqrt{ }$ & $\sqrt{ }$ & $\sqrt{ }$ & $\sqrt{ }$ & $\sqrt{ }$ & $\sqrt{ }$ & $\sqrt{ }$ & $\sqrt{ }$ & $\sqrt{ }$ & $\sqrt{ }$ & P.v & $\sqrt{ }$ & $\sqrt{ }$ & $\sqrt{ }$ \\
\hline 13-2-MM01(P. f) & $\sqrt{ }$ & $\sqrt{ }$ & $\sqrt{ }$ & $\sqrt{ }$ & $\sqrt{ }$ & $\sqrt{ }$ & $\sqrt{ }$ & $\sqrt{ }$ & $\sqrt{ }$ & $\sqrt{ }$ & $\sqrt{ }$ & $\sqrt{ }$ & $\sqrt{ }$ & $\sqrt{ }$ & $\sqrt{ }$ & $\sqrt{ }$ & $\sqrt{ }$ & $\sqrt{ }$ & $\sqrt{ }$ \\
\hline 13-2-MM02(NE) & $\sqrt{ }$ & $\sqrt{ }$ & $\sqrt{ }$ & $\sqrt{ }$ & $\sqrt{ }$ & $\sqrt{ }$ & $\sqrt{ }$ & $\sqrt{ }$ & $\sqrt{ }$ & $\sqrt{ }$ & $\sqrt{ }$ & $\sqrt{ }$ & $\sqrt{ }$ & $\sqrt{ }$ & $\sqrt{ }$ & $\sqrt{ }$ & $\sqrt{ }$ & $\sqrt{ }$ & $\sqrt{ }$ \\
\hline 13-2-MM03 (P. f) & $\sqrt{ }$ & $\sqrt{ }$ & $\sqrt{ }$ & $\sqrt{ }$ & $\sqrt{ }$ & $\sqrt{ }$ & $\sqrt{ }$ & $\sqrt{ }$ & $\sqrt{ }$ & $\sqrt{ }$ & $\sqrt{ }$ & $\sqrt{ }$ & $\sqrt{ }$ & $\sqrt{ }$ & $\sqrt{ }$ & $\sqrt{ }$ & $\sqrt{ }$ & $\sqrt{ }$ & $\sqrt{ }$ \\
\hline 13-2-MM04 (P. v) & $\sqrt{ }$ & P.f & $\sqrt{ }$ & $\sqrt{ }$ & $\sqrt{ }$ & $\sqrt{ }$ & $\sqrt{ }$ & $\sqrt{ }$ & $\sqrt{ }$ & P.m & $\sqrt{ }$ & $\sqrt{ }$ & $\sqrt{ }$ & $\sqrt{ }$ & $\sqrt{ }$ & $\sqrt{ }$ & $\sqrt{ }$ & $\sqrt{ }$ & $\sqrt{ }$ \\
\hline 13-2-MM05 (P. o) & P.m & $\sqrt{ }$ & $\sqrt{ }$ & $\sqrt{ }$ & $\sqrt{ }$ & P.V & $\sqrt{ }$ & $\sqrt{ }$ & P.V & $\sqrt{ }$ & $\sqrt{ }$ & P.V & $\sqrt{ }$ & P.V & P.m & P.V & $\sqrt{ }$ & P.k & P.V \\
\hline 13-2-MM06 (P.f) & $\sqrt{ }$ & $\sqrt{ }$ & $\sqrt{ }$ & $\sqrt{ }$ & $\sqrt{ }$ & $\sqrt{ }$ & $\sqrt{ }$ & $\sqrt{ }$ & $\sqrt{ }$ & $\sqrt{ }$ & $\sqrt{ }$ & $\sqrt{ }$ & $\sqrt{ }$ & $\mathrm{NE}$ & $\sqrt{ }$ & $\sqrt{ }$ & $\sqrt{ }$ & $\sqrt{ }$ & $\sqrt{ }$ \\
\hline 13-2-MM08 (NE) & $\sqrt{ }$ & $\sqrt{ }$ & $\sqrt{ }$ & $\sqrt{ }$ & $\sqrt{ }$ & $\sqrt{ }$ & $\sqrt{ }$ & $\sqrt{ }$ & $\sqrt{ }$ & $\sqrt{ }$ & $\sqrt{ }$ & $\sqrt{ }$ & $\sqrt{ }$ & $\sqrt{ }$ & P.V & $\sqrt{ }$ & $\sqrt{ }$ & $\sqrt{ }$ & P.V \\
\hline 13-2-MM10 (P. v) & P.O & $\sqrt{ }$ & $\sqrt{ }$ & $\sqrt{ }$ & $\sqrt{ }$ & $\sqrt{ }$ & $\sqrt{ }$ & $\sqrt{ }$ & $\sqrt{ }$ & $\sqrt{ }$ & $\sqrt{ }$ & $\sqrt{ }$ & $\sqrt{ }$ & $\sqrt{ }$ & P.o & $\sqrt{ }$ & $\sqrt{ }$ & $\sqrt{ }$ & $\sqrt{ }$ \\
\hline 13-2-MM14 (P. v) & $\sqrt{ }$ & $\sqrt{ }$ & $\sqrt{ }$ & $\sqrt{ }$ & $\sqrt{ }$ & $\sqrt{ }$ & $\sqrt{ }$ & P.o & $\sqrt{ }$ & $\sqrt{ }$ & $\sqrt{ }$ & $\sqrt{ }$ & $\sqrt{ }$ & $\sqrt{ }$ & P.o & $\sqrt{ }$ & $\sqrt{ }$ & $\sqrt{ }$ & $\sqrt{ }$ \\
\hline 13-2-MM15 (P. f) & $\sqrt{ }$ & $\sqrt{ }$ & $\sqrt{ }$ & $\sqrt{ }$ & $\sqrt{ }$ & $\sqrt{ }$ & $\sqrt{ }$ & $\sqrt{ }$ & $\sqrt{ }$ & $\sqrt{ }$ & $\sqrt{ }$ & $\sqrt{ }$ & $\sqrt{ }$ & $\sqrt{ }$ & $\sqrt{ }$ & $\sqrt{ }$ & $\sqrt{ }$ & $\sqrt{ }$ & $\sqrt{ }$ \\
\hline
\end{tabular}

$\checkmark$ indicates correct identification; NE indicates that the slide is negative for Plasmodium spp; different alphabets in the title row indicate the different staff in participating laboratories.

Table 2 PCR primers used and expected product size in malaria diagnosis

\begin{tabular}{|c|c|c|c|}
\hline Reaction & $\begin{array}{l}\text { Primer } \\
\text { name }\end{array}$ & Primer sequence & $\begin{array}{l}\text { Product } \\
\text { length }\end{array}$ \\
\hline \multirow[t]{2}{*}{ First PCR } & rPLU5 & 5'-CCTGTTGTTGCCTTAAACTTC-3' & $1200 \mathrm{bp}$ \\
\hline & rPLU6 & 5'-TTAAAATTGTTGCAGTTAAAACG-3' & \\
\hline \multirow[t]{8}{*}{ Nested PCR } & rFAL1 & $\begin{array}{l}\text { 5'-TTAAACTGGTTTGGGAAAACCAAAT } \\
\text { ATATT-3' }\end{array}$ & 205 bp \\
\hline & rFAL2 & $\begin{array}{l}\mathbf{5}^{\prime} \text {-ACACAATGAACTCAATCATGACTAC } \\
\text { CCGTC-3' }\end{array}$ & \\
\hline & rVIV1 & $\begin{array}{l}\text { 5'-CGCTTCTAGCTTAATCCACATAACT } \\
\text { GATAC-3' }\end{array}$ & $120 \mathrm{bp}$ \\
\hline & rVIV2 & $\begin{array}{l}\mathbf{5}^{\prime}-\mathrm{ACTTCCAAGCCGAAGCAAAGAAA} \\
\text { GTCCTTA-3' }\end{array}$ & \\
\hline & rMAL1 & $\begin{array}{l}\text { 5'-ATAACATAGTTGTACGTTAAGAAT } \\
\text { AACCGC-3' }\end{array}$ & $141 \mathrm{bp}$ \\
\hline & rMAL2 & $\begin{array}{l}\mathbf{5}^{\prime} \text {-AAAATTCCCATGCATAAAAAATTAT } \\
\text { ACAAA-3' }\end{array}$ & \\
\hline & rOVA1 & $\begin{array}{l}\mathbf{5}^{\prime} \text {-ATCTCTTITGCTATTITITAGTATTG } \\
\text { GAGA-3' }\end{array}$ & $800 \mathrm{bp}$ \\
\hline & rOVA2 & $\begin{array}{l}\mathbf{5}^{\prime}-\text { GGAAAAGGACACATTAATTGTATC } \\
\text { CTAGTG-3' }\end{array}$ & \\
\hline
\end{tabular}

\section{Results}

In total, 19 provincial reference laboratories that met all requirement for inclusion in the network such as laboratory room, devices, organization, and technical demands were established in 2011, 2012 and 2013, respectively (Figure 2). All these laboratories had independent rooms for the following: sample storage, microscopy and molecular biological detection (PCR), and essential devices, such as microscopes. They also had normal and low or ultralow temperature refrigerators, water baths, autoclaves, high-speed centrifuges, DNA amplification system, electrophoretic imaging system.

\section{Laboratory staff}

A total of 168 staff from 19 provincial malaria laboratories registered in the programme. Each laboratory had four to 14 individuals $(8.84 \pm 2.87$ persons/laboratory) ranging in ages from $25-59$ years $(40.26 \pm 10.62)$ with $61.9 \%$ being males $(104 / 168)$ and $38.1 \%$ females $(64 / 168)$. Among them 45.8\% (77/168) had bachelors' degree and $35.7 \%(60 / 168)$ had a graduate degree and the remaining had a college degree. In addition, 96 individuals (5.05/laboratory) were full-time staff of the malaria laboratory while 72 worked part-time. The position of the individuals was responsible for laboratory management, microscopy, 


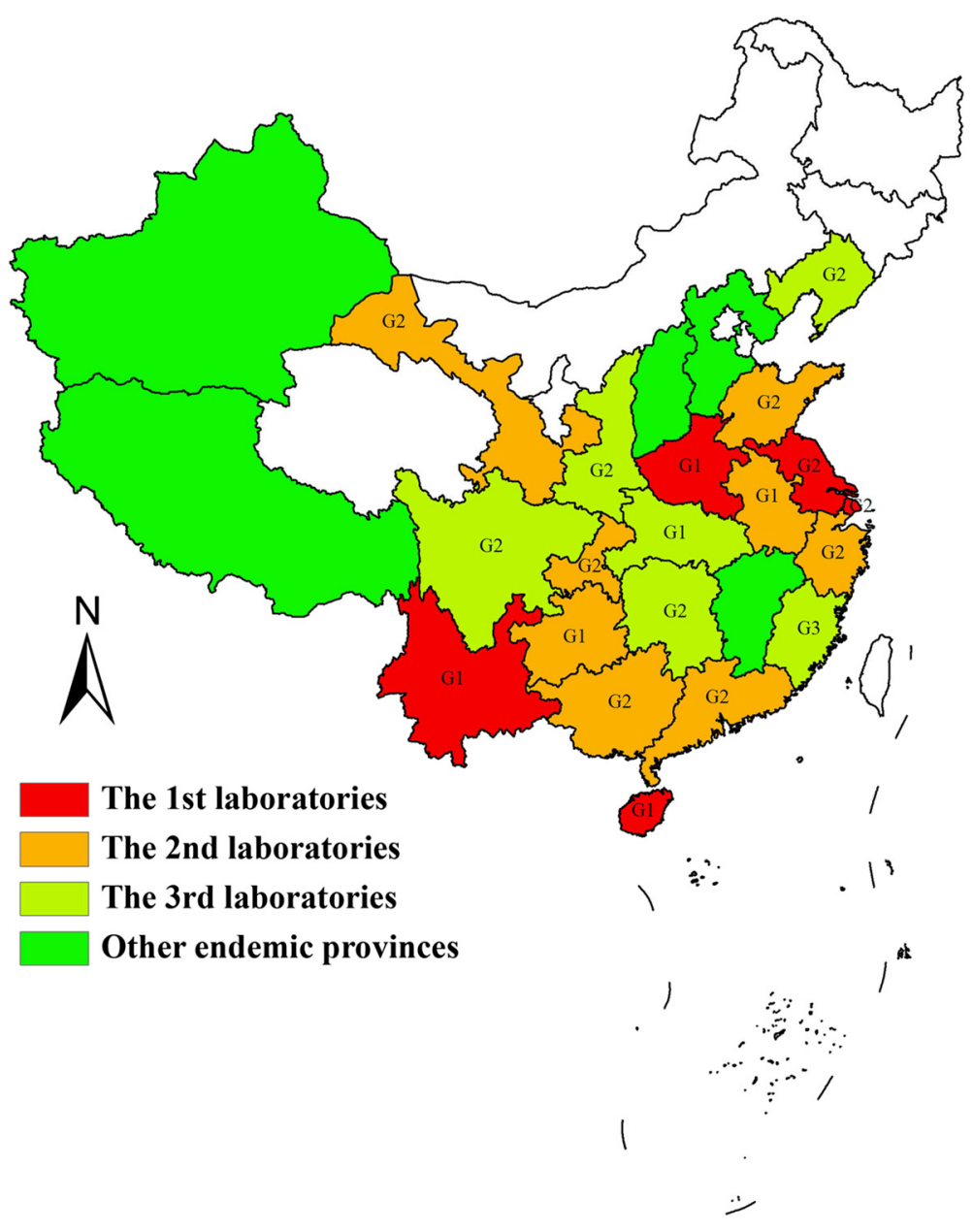

Figure 2 Distribution and classification of the provincial malaria diagnosis reference laboratories.

molecular biological detection, and management of QA and biosafety, respectively.

The 19 laboratories were classified into three groups (G1 3) (Figure 2) based on the geographical malaria epidemiology area described in the Action Plan of Malaria Elimination (2010-2020) and a previous publication [16]. These demographics among groups were not statistically significant. Age: Kruskal-Wallis Test, $\chi^{2}=0.1539$, $P=0.9259$. Gender: Fisher's exact probability, $P=0.7677$. Education level: Fisher's exact probability, $P=0.3238$. Work style (full-time or part-time): Fisher's exact probability, $P=0.6412$.

\section{Microscopy assessment}

In total, only two participants correctly identified all 20 slides. Seven failed in one slide, six incorrectly identified two slides, two individuals failed in three slides, and one each incorrectly identified four and six slides, respectively. Particularly, 12 participants identified the Plasmodium vivax-positive slide marked '13-1-MM10' as Plasmodium ovale. The $P$. ovale positive slide of '13-2-MM05' was the most difficult for participants with nine failing to identify it and most of them (6/9) incorrectly identifying it as $P$. vivax (Table 1). However, no significant differences in error percentages were observed among the three groups (Fisher's exact probability, $P=0.2338$ ).

\section{PCR assessment}

Among the results reported, 84.21\% (48/57) of samples were detected correctly; $63.16 \%(12 / 19)$ of staff detected all samples correctly and $26.32 \%$ (5/19) failed in one sample. Interestingly, two participants detected only one sample correctly (Table 3). No significant differences were found among the three groups (Fisher's exact probability, $P=0.3569$ ).

\section{Discussion}

This is the first major diagnosis quality assessment in China malaria diagnosis reference laboratory network, and such activities are critical for the reduction or elimination of the disease in the country. As there are 5.5 persons on average in each laboratory the participants in the study 
Table 3 Malaria diagnosis by PCR

\begin{tabular}{|c|c|c|c|c|c|c|c|c|c|c|c|c|c|c|c|c|c|c|c|}
\hline & \multicolumn{6}{|l|}{ G1 } & \multicolumn{12}{|l|}{ G2 } & \multirow{2}{*}{$\begin{array}{l}\text { G3 } \\
\text { K1 }\end{array}$} \\
\hline & $\overline{\mathrm{C} 1}$ & M1 & 01 & P1 & R1 & $\overline{S 1}$ & $\overline{\mathrm{A} 1}$ & B1 & D1 & E1 & F1 & G1 & $\mathrm{H} 1$ & 11 & J1 & L1 & N1 & $\overline{\mathrm{Q1}}$ & \\
\hline Correct diagnosis & 2 & 2 & 3 & 2 & 1 & 2 & 3 & 3 & 2 & 1 & 3 & 3 & 3 & 3 & 3 & 3 & 3 & 3 & 3 \\
\hline Wrong diagnosis & 1 & 1 & 0 & 1 & 2 & 1 & 0 & 0 & 1 & 2 & 0 & 0 & 0 & 0 & 0 & 0 & 0 & 0 & 0 \\
\hline
\end{tabular}

Different alphabets in the title row indicate the different staff in participating laboratories.

can be seen as representative of capacity of their own laboratory, even though not randomly drawn. The results reported here provide insights into the efficacy of malaria diagnosis using microscopy and PCR methods, and highlight areas that require improvement.

Currently, participants in the provincial laboratories can efficiently identify most Plasmodium species by light microscopy with an accuracy level of 90.79\% (345/380). Besides, microscopists ( $\mathrm{O}, \mathrm{P}$ and $\mathrm{Q})$, who achieved the top level 1, 2 or 3 efficiency in diagnosing malaria through a microscope and were assessed in China by a WHOCertified Level-1/expert microscopist in 2012 [17], in the present programme maintained high efficiency levels. Moreover, in the three external quality assessment programmes (EQAPs) for malaria microscopy (2012-2013) organized by WHO, the accuracy of identifying Plasmodium species by microscopists in national laboratory was 91.67 (55/60), 86.67 (39/45) and 95.56\% (43/45). Overall, these demonstrated the high competency of Plasmodium species identification by Chinese malaria microscopists.

However, malaria diagnosis in China still faces the challenges. First, the microscopy competency at lower levels needs improvement. The average accuracy of Plasmodium detection in China ranges from 62 to 66\%, which is based on three national technique competitions for diagnosis of parasitic diseases conducted in 2011 [18], 2012 [16] and 2013 (unpublished). In these competitions, the accuracy of Plasmodium falciparum and $P$. vivax species identification was about $65 \%[16,18]$. In each competition, participants from below provincial levels had the lower scores. Since a positive case of malaria in an elimination programme is defined as the presence of parasites in the blood regardless of the presence or absence of clinical symptoms $[4,19,20]$, to improve the basic capability for malaria diagnosis, it is essential to equip existing staff with reliable identification techniques.

Second, it is difficult to identify rare Plasmodium species in China. Although total malaria cases reported in recent years decreased markedly, malaria importation poses a constant threat to mainland China with the proportion increasing every year. The major species imported to China are the dominant $P$. falciparum from African continent and $P$. vivax from Asian countries, but other species, such as Plasmodium malariae and $P$. ovale have also been reported $[1,21,22]$.
Plasmodium ovale has been reported throughout the world, and its natural distribution [23] is limited to subSaharan Africa [24-27] and the islands of the western Pacific [28-30]. In China, $P$. ovale received little attention primarily due to sporadic malaria cases associated with this species [31]. The incidence of $P$. ovale malaria has increased due to importation by travellers to sub-Saharan Africa [32-36]. The symptoms of $P$. ovale malaria include common cold-like mild symptoms and are accompanied with low parasitaemia, and individuals infected this species are given the same treatment as $P$. vivax [37]. It has been reported previously that it is difficult to differentiate $P$. ovale from $P$. vivax by examining peripheral blood films stained with Giemsa [37]. Consistent with this report, the P. ovale malaria cases in China were misdiagnosed as $P$. vivax malaria $[38,39]$ as was the case in this present programme. Therefore, for the successful elimination of malaria in China, it is essential to pay attention to the identification of $P$. ovale, and strengthen the training at different levels.

The diagnosis of malaria parasites by nested PCR in the present assessment is at medium level with an accuracy of $84.21 \%$ (48/57). The ease and speed of PCR makes it an important tool in malaria elimination programmes and should be improved to detect asymptomatic infections. Since various PCR methods have been developed for malaria diagnosis [40-44], it is necessary to compare the benefits of different methods, optimize the protocol, and train staff in the reference laboratory network. Meanwhile, more samples with different densities should be included in future QA activities.

In addition, more comprehensive assessments including slides and dry blood spots with different parasite densities should be considered in future.

\section{Conclusion}

A malaria diagnosis reference laboratory network has been established in China and is in its initial stages. The identification of Plasmodium species using microscopy and PCR is at medium to high level. The biggest problem is the misdiagnosis of $P$. ovale as $P$. vivax microscopically. It is essential for more laboratories at different levels apply to join the network to obtain the required training and sustain malaria elimination in China. Special emphasis should be on the identification of locally rare Plasmodium species, such as $P$. ovale. 


\section{Competing interests}

The authors declare they have no competing interests. The findings and conclusions in this paper are those of the authors and do not represent the official views. The funders had no role in study design, data collection and analysis, decision to publish, or preparation of the manuscript.

\section{Authors' contributions}

$J Y, H Y$ and $Z X$ designed the programme. JY, HY, ML, FH and SZ performed and participated the programme. JY, HY and HX analysed the data. JY and ZX drafted and revised the paper. All authors read and approved the final manuscript.

\section{Acknowledgements}

This work was supported by the National S and T Major Programme (Grant No. 2012ZX10004-220 and 2012ZX10004-201). The authors thank the provincial malaria laboratories located in provincial CDCs/institutes of parasitic diseases in Liaoning, Shanghai, Jiangsu, Zhejiang, Anhui, Shandong, Henan, Hubei, Hunan, Guangdong, Guangxi, Hainan, Chongqing, Sichuan, Yunnan, Guizhou, Shaanxi, Sichuan, and Gansu provinces, and thank reviewers for their comments.

\section{Received: 8 December 2014 Accepted: 9 January 2015 Published online: 28 January 2015}

\section{References}

1. Yin JH, Yang MN, Zhou SS, Wang Y, Feng J, Xia ZG. Changing malaria transmission and implications in China towards National Malaria Elimination Programme between 2010 and 2012. PLoS One. 2013;8:e74228.

2. Diouf G, Kpanyen PN, Tokpa AF, Nie S. Changing landscape of malaria in China: progress and feasibility of malaria elimination. Asia Pac J Public Health. 2014;26:93-100.

3. WHO. WHO procedures for certification of malaria elimination. Weekly Epidemiological Record. 2014;89:321-5.

4. Yin J, Xia Z, Yan H, Huang Y, Lu L, Geng Y, et al. Verification of clinically diagnosed cases during malaria elimination programme in Guizhou Province of China. Malar J. 2013;12:130.

5. Ohrt C, Purnomo, Sutamihardja MA, Tang D, Kain KC. Impact of microscopy error on estimates of protective efficacy in malaria-prevention trials. J Infect Dis. 2002;186:540-6.

6. Ohrt C, Obare P, Nanakorn A, Adhiambo C, Awuondo K, O'Meara WP, et al. Establishing a malaria diagnostics centre of excellence in Kisumu, Kenya. Malar J. 2007:6:79

7. Kitua A, Ogundahunsi O, Lines J, Mgone C. Conquering malaria: enhancing the impact of effective interventions towards elimination in the diverse and changing epidemiology. J Glob Infect Dis. 2011;3:161-5.

8. Stresman G, Kobayashi T, Kamanga A, Thuma PE, Mharakurwa S, Moss WJ, et al. Malaria research challenges in low prevalence settings. Malar J. 2012;11:353.

9. Kamau E, Tolbert LS, Kortepeter L, Pratt M, Nyakoe N, Muringo L, et al. Development of a highly sensitive genus-specific quantitative reverse transcriptase real-time PCR assay for detection and quantitation of Plasmodium by amplifying RNA and DNA of the 18S rRNA genes. J Clin Microbiol. 2011:49:2946-53.

10. Fuehrer HP, Starzengruber P, Swoboda P, Khan WA, Matt J, Ley B, et al. Indigenous Plasmodium ovale malaria in Bangladesh. Am J Trop Med Hyg. 2010;83:75-8.

11. Snounou G, Viriyakosol S, Zhu XP, Jarra W, Pinheiro L, do Rosario VE, et al. High sensitivity of detection of human malaria parasites by the use of nested polymerase chain reaction. Mol Biochem Parasitol. 1993:61:315-20.

12. Zakeri S, Najafabadi ST, Zare A, Djadid ND. Detection of malaria parasites by nested PCR in south-eastern, Iran: evidence of highly mixed infections in Chahbahar district. Malar J. 2002;1:2.

13. Ashraf S, Kao A, Hugo C, Christophel EM, Fatunmbi B, Luchavez J, et al. Developing standards for malaria microscopy: external competency assessment for malaria microscopists in the Asia-Pacific. Malar J. 2012;11:352.

14. WHO. Basic Malaria Microscopy: Part 1. Learner's Guide. 2nd ed. 20 Avenue Appia, 1211 Geneva 27, Switzerland: WHO Press; 2010.

15. Tang LH. Diagnosis, Treatment and Management of Imported Malaria Cases. Shanghai: Shanghai Scientific and Technical Publishers; 2010.

16. Zhang SS, Xia ZG, Yin JH, Yan H, Zhou SS, Li SZ, et al. Analysis report of the national technique competition for diagnosis of parasitic diseases in 2012: I.
Capability analysis of Plasmodium detection (in Chinese). Zhongguo Ji Sheng Chong Xue Yu Ji Sheng Chong Bing Za Zhi. 2013;31:131-4.

17. Workshop on external competency assessment of malaria microscopists in China. http://www.ipd.org.cn/Article/zyxw/zyxw/201212/2644.html

18. Fu Q, Li SZ, Wang Q, Zhang L, Liu W, Zheng X, et al. Report of analysis of National Technique Competition for Diagnosis of Parasitic Diseases in 2011-Il Analysis of capabilities of Plasmodium detection (in Chinese). Zhongguo Xue Xi Chong Bing Fang Zhi Za Zhi. 2012;24:274-8.

19. WHO. Malaria elimination - A field manual for low and moderate endemic countries. 20 Avenue Appia, 1211 Geneva 27, Switzerland: WHO Press; 2007.

20. WHO. Disease surveillance for malaria elimination - an operational manual. 20 Avenue Appia, 1211 Geneva 27, Switzerland: WHO Press; 2012.

21. Xia ZG, Feng J, Zhou SS. Malaria situation in the People's Republic of China in 2012 (in Chinese). Zhongguo Ji Sheng Chong Xue Yu Ji Sheng Chong Bing Za Zhi. 2013;31:413-8.

22. Xia ZG, Yang MN, Zhou SS. Malaria situation in the People's Republic of China in 2011 (in Chinese). Zhongguo Ji Sheng Chong Xue Yu Ji Sheng Chong Bing Za Zhi. 2012;30:419-22.

23. Lysenko AJ, Beljaev AE. An analysis of the geographical distribution of Plasmodium ovale. Bull World Health Organ. 1969;40:383-94.

24. Cornu M, Combe A, Couprie B, Moyou-Somo R, Carteron B, Van Harten WH, et al. Epidemiological aspects of malaria in 2 villages of the Manyemen forest region (Cameroon, southwest province) (in French). Med Trop (Mars). 1986;46:131-40

25. Richard-Lenoble D, Kombila M, Chandenier J, Gay F, Billiault X, Nguiri C, et al. Malaria in Gabon. 2. Evaluation of the qualitative and quantitative prevalence of parasites in the total school and preschool population of the country (in French). Bull Soc Pathol Exot Filiales. 1987:80:532-42.

26. Afari EA, Nakano T, Binka F, Owusu-Agyei S, Asigbee J. Seasonal characteristics of malaria infection in under-five children of a rural community in southern Ghana. West Afr J Med. 1993;12:39-42.

27. Chin W, Contacos PG. A recently isolated West African strain of Plasmodium ovale. Am J Trop Med Hyg. 1966;15:1-2.

28. Alves W, Schinazi LA, Aniceto F. Plasmodium ovale infections in the Philippines. Bull World Health Organ. 1968;39:494-5.

29. Cabrera BD, Arambulo 3rd PV. Malaria in the Republic of the Philippines. A review. Acta Trop. 1977;34:265-79.

30. Lupasco G, Bossie-Agavriloaei A, Lenghel I, Smolinschi M. On a case of malaria due to Plasmodium ovale contracted in Guinea (in French). Arch Roum Pathol Exp Microbiol. 1966;25:561-6.

31. Tang LH, Xu LQ, Chen YD. Parasitic disease control and research in China (in Chinese). No. 16 Xizhimen South Street. Beijing: Beijing Science \& Technology Press; 2012.

32. Cadigan FC, Desowitz RS. Two cases of Plasmodium ovale malaria from central Thailand. Trans R Soc Trop Med Hyg. 1969;63:681-2.

33. Kawamoto F, Miyake $H$, Kaneko O, Kimura M, Nguyen TD, Nguyen TD, et al Sequence variation in the $18 \mathrm{~S}$ rRNA gene, a target for PCR-based malaria diagnosis, in Plasmodium ovale from southern Vietnam. J Clin Microbiol. 1996;34:2287-9.

34. Gleason NN, Fisher GU, Blumhardt R, Roth AE, Gaffney GW. Plasmodium ovale malaria acquired in Viet-Nam. Bull World Health Organ. 1970:42:399-403.

35. Fairley NH. A case of malaria due to Plasmodium ovale Stephens 1922 . Br Med J. 1933:2:101-2.

36. Patterson JE, Bia FJ, Miller K, McPhedran P. Relapsing malaria infection acquired in Kenya. Yale J Biol Med. 1987;60:245-53.

37. Collins WE, Jeffery GM. Plasmodium ovale: parasite and disease. Clin Microbiol Rev. 2005;18:570-81.

38. Yao LN, Zhang LL, Ruan W, Chen HL, Lu QY, Yang TT. Species identification in 5 imported cases previously diagnosed as Vivax malaria by parasitological and nested PCR techniques (in Chinese). Zhongguo Ji Sheng Chong Xue Yu Ji Sheng Chong Bing Za Zhi. 2013;31:221-3. 234.

39. Zhou RM, Zhang HW, Deng Y, Qian D, Liu Y, Chen WQ, et al. Laboratory detection on two cases with imported Plasmodium ovale infection (in Chinese). Zhongguo Ji Sheng Chong Xue Yu Ji Sheng Chong Bing Za Zhi. 2013:31:127-30.

40. Aydin-Schmidt B, Xu W, Gonzalez IJ, Polley SD, Bell D, Shakely D, et al. Loop-mediated isothermal amplification (LAMP) accurately detects malaria DNA from filter paper blood samples of low density parasitaemias. PLoS One. 2014:9:e103905.

41. Poschl B, Waneesorn J, Thekisoe O, Chutipongvivate S, Karanis P. Comparative diagnosis of malaria infections by microscopy, nested PCR, and LAMP in northern Thailand. Am J Trop Med Hyg. 2010;83:56-60. 
42. Singh R, Singh DP, Gupta R, Savargaonkar D, Singh OP, Nanda N, et al. Comparison of three PCR-based assays for the non-invasive diagnosis of malaria: detection of Plasmodium parasites in blood and saliva. Eur J Clin Microbiol Infect Dis. 2014:33:1631-9.

43. Anthony C, Mahmud R, Lau YL, Syedomar SF, Sri La Sri Ponnampalavanar S. Comparison of two nested PCR methods for the detection of human malaria. Trop Biomed. 2013;30:459-66.

44. Alemayehu S, Feghali KC, Cowden J, Komisar J, Ockenhouse CF, Kamau E. Comparative evaluation of published real-time PCR assays for the detection of malaria following MIQE guidelines. Malar J. 2013;12:277.

\section{Submit your next manuscript to BioMed Central} and take full advantage of:

- Convenient online submission

- Thorough peer review

- No space constraints or color figure charges

- Immediate publication on acceptance

- Inclusion in PubMed, CAS, Scopus and Google Scholar

- Research which is freely available for redistribution 